\title{
Process Module Construction Kit for Modular Micro Assembly Systems
}

\author{
Raphael Adamietz ${ }^{*}$, Tobias Iseringhausen, and Alexander Verl \\ Fraunhofer-Institute für Produktionstechnik und Automatisierung IPA, \\ Nobelstr. 12, 70569 Stuttgart, Germany \\ adamietz@ipa.fraunhofer.de \\ www.ipa.fraunhofer.de
}

\section{Introduction}

The production environment in Europe is characterized by a number of different challenges. Production volumes are hardly predictable due to the turbulent market [1]. Product life cycles become increasingly shorter [2]. Customers demand more individual and customized products, which leads to increasingly diversified product pallets [3]. The occurrence of changes on product and process, even for running productions, increases continuously [4]. At the same time the field of tension between assurance of quality, reduction of lead times and reduction of cost remains present [5].

The trend of miniaturization with the concurrent trend of integration of functions is a central topic in the product development in different fields of application [6], like optics, electronics, medical technology, bio technology, information technology and aeronautical technology. With ongoing miniaturization many companies face challenges of precision and ultra-precision assembly technology. Therewith increases the cost and complexity of the required process equipment and the demands to skilled personnel [7].

The development of the markets in micro system technology shows that many new and innovative developments in the field of hybrid microsystems cannot achieve a satisfactory success [8]. This can be attributed to the high complexity of microtechnical products and processes, a lack of interdisciplinary knowledge in process development, limited flexibility of the applied manufacturing and assembly systems and the high investment risk due to uncertain forecasts of growth [9]. From the economic point of view, often only mass production is reasonable [9].

Modular micro assembly systems are often regarded as suitable link between the requirements of the market environment and the current state of development in micro production technology [10-12]. Approaches such as the Agile Assembly Architecture [11], Evolvable Assembly Systems [10] or the Reconfigurable Micro Assembly System [12] are parts of ongoing research and have been partly transferred to commercial products.

Modular production systems are characterized by standardized components and defined interfaces [13]. Single modules can be exchanged rapidly and re-installed in

\footnotetext{
* Corresponding author.
} 
other systems. This provides many advantages over the whole product life cycle. In the field of micro production these effects are increased, due to the increased investment cost and higher complexity of the production equipment.

However, the market share of modular machines does not match the predictions [14]. This can be mainly attributed to the fact that the initial investment into a modular machine is significantly higher than into a special purpose machine. Repetition effects by re-use of equipment in form of process modules are necessary to make modular machines more attractive.

The authors of this paper suggest an open interface which allows the integration of process equipment of different providers into machinery of different providers. This would significantly improve the possibility to continuously adapt assembly machines. Particularly companies with broad product ranges could potentially benefit strongly.

Based on this open interface a common platform for the exchange of process modules is suggested [15]. By a certification step, the compatibility of the offered process modules and platforms is ensured. Providers and users of modular production equipment can then offer and exchange their equipment. This way the application of one process module is not bound to one platform, but can be transferred across different platforms of different providers. This would have a strong effect on the availability of process equipment.

To support the development and set-up of process modules, a construction kit is proposed. Within this paper, the basic concept of a construction kit for process modules is described. Furthermore examples of configurations of process modules based on the construction kit are presented.

\section{Qualitative and Quantitative Analysis}

The approach of modular micro assembly machines has been compared to state-ofthe-art micro assembly machinery in previous work. For qualitative analysis a $\mathrm{SWOT}^{1}$ analysis was presented and for quantitative analysis a net present value analysis was performed. [15]

The quantitative analysis showed potential for risk management by the application of a modular system. If for example the production volumes deviate from the predictions, the modular approach allows adapting to these changes.

The qualitative analysis revealed many opportunities such as simultaneous engineering, standardized modules which can be used already during process development and reuse of production equipment. However, the analysis also revealed several threats, like decrease of process stability and product quality which might be caused by the changes of the assembly system. The largest threat, however, was that process modules might not be available as required. As an approach to improve this situation, the concept of a process module construction kit is presented here.

\footnotetext{
${ }^{1}$ SWOT - Strength, Weaknesses, Opportunities, Threats.
} 


\section{Concept of a Process Module Construction Kit}

\subsection{Complex Interface}

Also proposed within previous work, was the 'Complex Interface' [15]. It consists of three concepts: The 'mechanical interface', the 'supply interface' and the 'control interface'.

The 'mechanical interface' comprises the definition of a generic, blank module. Spaces for process, feeding and control equipment as well as working spaces are defined. Within the 'supply interface' a supply connector is defined which includes supply of compressed air and electricity as well as connection to Ethernet and field bus. The 'control interface' defines the interface and function blocks for control integration. The overall complex interface definition is a prerequisite for cross-platform integration. It allows machine constructors to provide a compliant interface to a common process module specification. Furthermore, it allows third parties to develop and to build process modules for different machines providing the complex interface.

\subsection{Process Module Construction Kit}

The effort required to develop and to set up process modules could be potentially reduced by a construction kit. A concept for such a construction kit has been designed and is presented here. The design process is depicted in Fig. 1 and Fig. 2.

It is assumed the requirements and boundary conditions have been determined and the process equipment has been chosen as the pre-condition for application of the construction kit (1). Process equipment is here referred to as e.g. a dispenser or a gripper.

Within the next step it is checked if the chosen process equipment can be integrated to a process module according to the specifications (2). This comprises the mechanical specifications and interfaces, the supply of the process module and an integration of the control system. Many process module systems work with different pitches, making the choice of an applicable process module necessary (3).

If the result of the check against the specification is positive, the process module can be designed. It is the aim to provide as many pre-defined elements as possible with known properties to ease the design process. These 'reference solutions' (4) comprise components required to build up the process module, such as axis systems with different kinematics (xy-tables, xyz-systems, 6-axis-kinematics, ...), pre-defined portal elements, sensors and calibration equipment (TCP-measuring units, vision systems, ...), feeding equipment (waffle pack feeder, vibrational feeder) and supportive equipment (cleaning devices, trays). With this equipment a process module, based on reference solutions can be designed (5). 


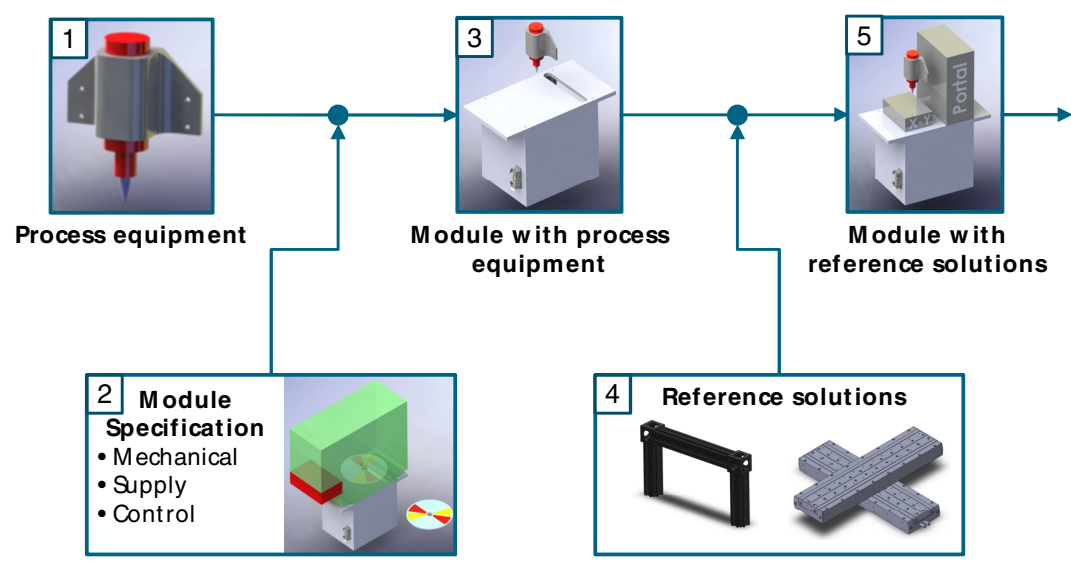

Fig. 1. Process module construction kit based on reference solution

To support the design and the set-up process a mechatronic tool interface is provided (6). It allows instant integration of process equipment, like e.g. a gripper, a dispenser or a camera system. While the complex interface provides interfacing between process module and machine, the mechatronic tool interface provides a standard interface between equipment on the process module itself. The interface is also comprehensive and provides a mechanical, supply and control interface. However, the specifications necessary for a tool interface differ from those of a module interface. The applied interface could be based for example on an ISO 29262 tool exchange interface [16]. An adaption to feed through field bus, Ethernet and media is additionally required.

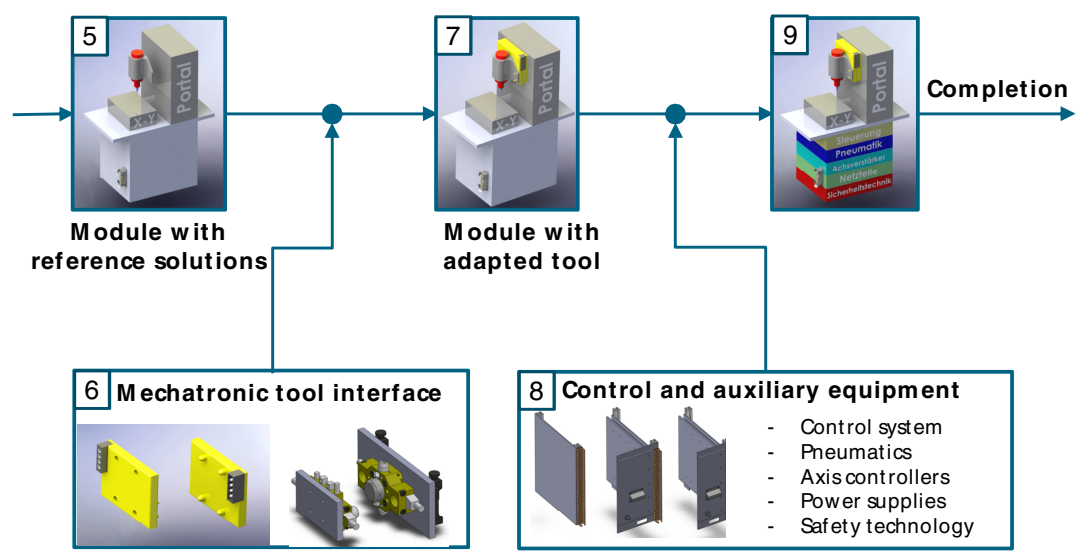

Fig. 2. Process modules based on reference solution

Once the process module with adapted tool is designed (7), control and auxiliary equipment are required. Reference solutions for control and auxiliary equipment are 
also provided (8). This comprises reference control programs, reference electrical and pneumatic circuitry, axis controllers, power supplies and safety technology.

The next step is the completion of the process module (9). This includes the design, manufacturing and set-up of the parts which are not covered in the construction kit. Furthermore testing is necessary before commissioning. Although the elements of the kit are depicted in a linear way in Fig 1 and Fig 2, re-iterations during the design phase are possible and part of the concept.

\section{Sample Configurations of Process Modules}

Different sample configurations of process modules have been realized as CAD models. One of these configurations is shown in Fig. 3. Based on the third module variant, a xyz-positioning system was applied. Additionally control, pneumatic and electric circuitry solutions are provided from the construction kit.

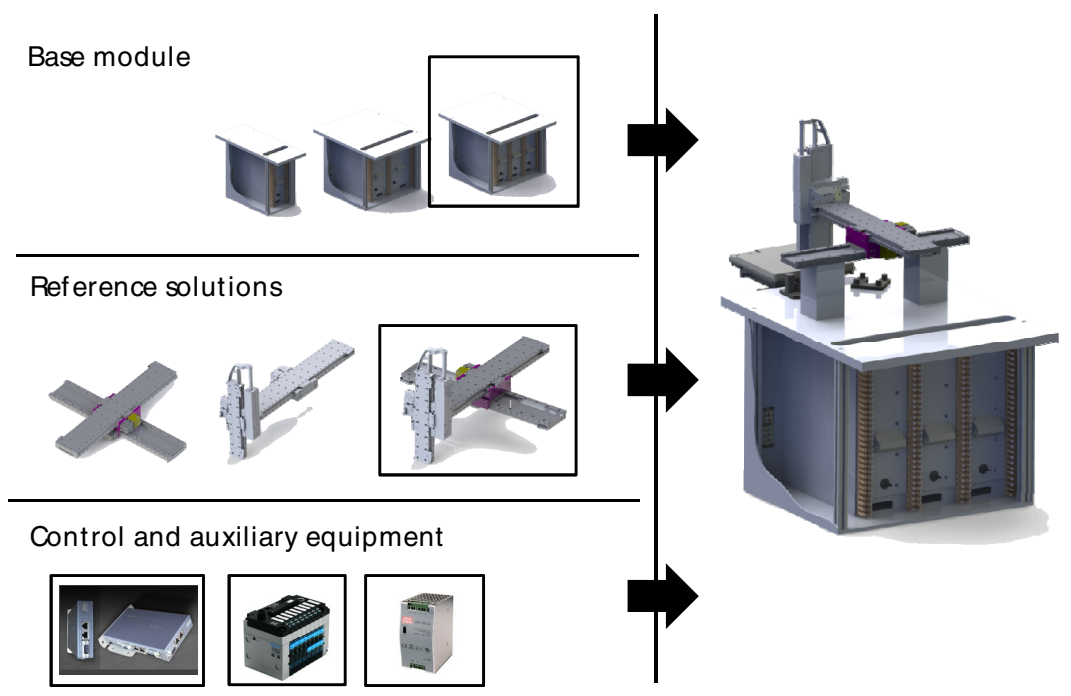

Fig. 3. Sample configuration of a process module

Regarding the adaption of tools, three different configurations are depicted in Fig 4. The adaption of a vision system together with a precision vacuum gripper is shown in Fig 4a. This could be applied for a pick and place process. Fig $4 \mathrm{~b}$ shows the same gripper combined with an extendible time-pressure dispensing unit. The combination could be used for a precision assembly operation using an adhesive. Fig $4 \mathrm{c}$ shows the dispenser in conjunction with the camera. This could be applied for a dispensing process supported by machine vision.

Although the number of elements in the construction kit is still very limited, many different reasonable combinations turned out to be possible. Still in the state of a model, first experience promises significant reduction of effort for the design of a process module. 


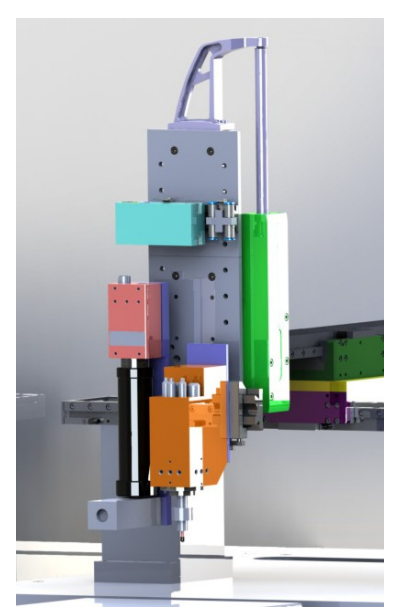

(a)

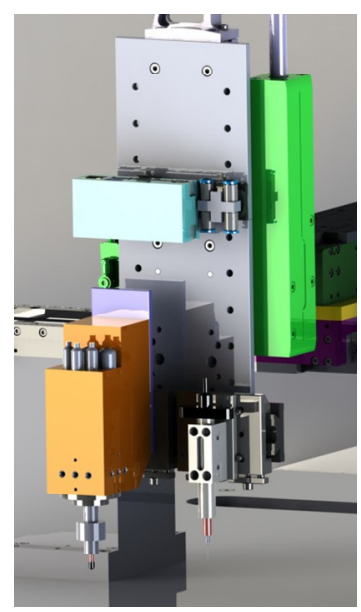

(b)

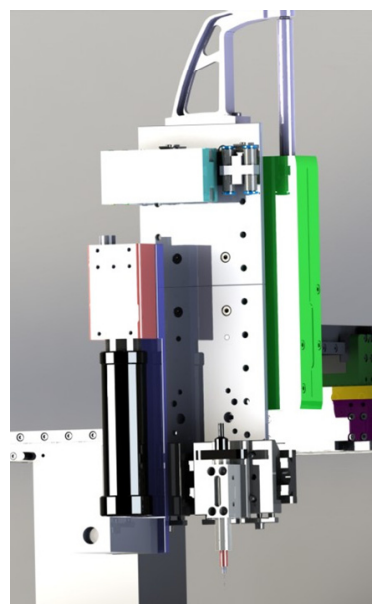

(c)

Fig. 4. Sample configurations of process modules based on the process module construction kit

\section{Conclusions and Outlook}

A concept for a construction kit for process modules is presented in this paper. The principle and the basic elements were described. Aim is to reduce the effort for design and set-up of process modules. The approach is to provide as many pre-defined elements as possible and to provide standard interfaces. However, it turned out that room for individual adaptions needs to be foreseen, as different applications have different requirements and that a one-fits-all solution is hardly achievable. Therefore the construction kit provides a pool of elements, which the developer can choose from and still provides room for individual design towards the specific requirements of the application.

To test the construction kit, a number of reference solutions were modeled. Based on these elements a number of different process modules were realized in CAD. The effort during modeling was significantly reduced by access to the pre-defined elements. However, the effect was not compared to commercially available solutions yet.

A prototype of a process module based on the construction kit will now be realized to evaluate the concept. The results will be used to re-iterate and optimize the concept and the included elements. An extension towards adaption of already existing solutions to new requirements will be included. The framework will furthermore be extended by supportive software tools for the construction kit and the specification micro assembly tasks.

Acknowledgements. This paper has emerged from the project «PRONTO/VOLPROD», which has been sponsored by the German Federal Ministry of Education and Research (BMBF) in the funding program "SpitzenCluster MicroTec SüdWest" and is administered by the project sponsor VDIVDE-IT in Berlin. 


\section{References}

[1] Nyhuis, P., Fronia, P., Pachow-Frauenhofer, J., Wulf, S.: Wandlungsfähige Produktionssysteme: Ergebnisse der BMBF-Vorstudie "Wandlungsfähige Produktionssysteme". wt Werkstattechnik online 99, 205-210 (2009)

[2] Wu, L., De Matta, R., Lowe, T.J.: Updating a modular product: How to set time to market and component quality. IEEE Transactions on Engineering Management 56, 298-311 (2009)

[3] Westkämper, E.: Modulare Produkte - Modulare Montage. wt Werkstattechnik Online 91, 479-482 (2001)

[4] Westkämper, E., Zahn, E.: Wandlungsfähige Produktionsunternehmen: Das Stuttgarter Unternehmensmodell. Springer (2008)

[5] Westkämper, E.: "Produktion im turbulenten Umfeld. Presented at the ATZ/MTZKonferenz AutomobilMontage 2007 (2007)

[6] Hesselbach, J., Wrege, J., Raatz, A.: Mikromontage. Montage in der industriellen Produktion, 463-482 (2006)

[7] Popa, D.O., Stephanou, H.E.: Micro and mesoscale robotic assembly. Journal of manufacturing processes 6, 52-71 (2004)

[8] Schilp, J.: Adaptive Montagesysteme für hybride Mikrosysteme unter Einsatz von Telepräsenz, vol. 244. Herbert Utz Verlag (2012)

[9] Hesselbach, J., Raatz, A., Wrege, J., Herrmann, H., Weule, H., Buchholz, C., Tritschler, H., Knoll, M., Elsner, J., Klocke, F.: Untersuchung zum internationalen Stand der Mikroproduktionstechnik

[10] Onori, M.: Final Report - EUPASS (Evolvable Ultra-Precision Assembly Systems), http: //cordis . europa.eu/documents / documentlibrary/127976311E N6.pdf2011

[11] Muir, P.F., Rizzi, A.A., Gowdy, J.W.: Minifactory: A precision assembly system adaptable to the product life cycle. In: Intelligent Systems \& Advanced Manufacturing, pp. 74-80 (1997)

[12] Gaugel, T., Dobler, H., Rohrmoser, B., Klenk, J., Neugebauer, J., Schäfer, W.: Advanced modular production concept for miniaturized products. In: Proc. of 2nd International Workshop on Microfactories, Fribourg, Switzerland, pp. 35-38 (2000)

[13] Nyhuis, P., Heinen, T., Reinhart, G., Rimpau, C., Abele, E., Wörn, A.: Wandlungsfähige Produktionssysteme: Theoretischer Hintergrund zur Wandlungsfähigkeit von Produktionssystemen. wt Werkstattstechnik online 98, 85-91 (2008)

[14] Kluge, S.: Methodik zur fähigkeitsbasierten Planung modularer Montage systeme (2011)

[15] Adamietz, R., Iseringhausen, T., Gerstenberg, S., Verl, A.: A First Step towards CrossPlatform Integration in Modular Micro-assembly Systems-Concept for a Process Module Construction Kit. In: Enabling Manufacturing Competitiveness and Economic Sustainability, pp. 35-40. Springer (2014)

[16] Deutsches Institut für Normung, DIN ISO 29262 - Fertigungsmittel für Mikrosysteme Schnittstelle zwischen Endeffektor und Handhabungsgerät. Beuth Verlag 